University for Business and Technology in Kosovo

UBT Knowledge Center

Nov 7th, 9:00 AM - 5:00 PM

\title{
Modelling business and management systems using Fuzzy cognitive maps: A critical overview
}

Peter P. Groumpos

University of Patras, groumpos@ece.upatras.gr

Follow this and additional works at: https://knowledgecenter.ubt-uni.net/conference

Part of the Databases and Information Systems Commons, and the Information Security Commons

\section{Recommended Citation}

Groumpos, Peter P., "Modelling business and management systems using Fuzzy cognitive maps: A critical overview" (2015). UBT International Conference. 113.

https://knowledgecenter.ubt-uni.net/conference/2015/all-events/113

This Event is brought to you for free and open access by the Publication and Journals at UBT Knowledge Center. It has been accepted for inclusion in UBT International Conference by an authorized administrator of UBT Knowledge Center. For more information, please contact knowledge.center@ubt-uni.net. 


\title{
Modelling business and management systems using Fuzzy cognitive maps: A critical overview
}

\author{
Peter P. Groumpos \\ Department of Electrical and Computer Engineering, University of Patras, Greece \\ groumpos@ece.upatras.gr
}

\begin{abstract}
A critical overview of modelling Business and Management (B\&M) Systems using Fuzzy Cognitive Maps is presented. A limited but illustrative number of specific applications of Fuzzy Cognitive Maps in diverse B\&M systems, such as e business, performance assessment, decision making, human resources management, planning and investment decision making processes is provided and briefly analyzed. The limited survey is given in a table with statics of using FCMs in B\&M systems during the last 15 years. The limited survey shows that the applications of Fuzzy Cognitive Maps to today's Business and Management studies has been steadily increased especially during the last 5-6 years. Interesting conclusions and future research directions are highlighted.
\end{abstract}

Keywords: Business Modelling, Management Systems, Fuzzy Cognitive Maps

\section{Introduction}

Modeling dynamic complex systems can be difficult in a computational sense and today many quantitative techniques exist.

Well-understood systems may be open to any of the mathematical programming techniques of operations study. First, developing the model is the most difficult task. It usually requires a great effort and specialized knowledge from the specific area of interest. This is the case when trying to model Business and Management (B\&M) processes.

Secondly, these systems are often nonlinear, in which case a quantitative model is not easily available and often may not be possible to be attained. Thirdly these (nonlinear?) systems by necessity involve feedback controls. In our case, of modelling B\&M is not an easy task at all. Fourthly simulating these systems with real data is almost a next to impossible task to be performed especially today in the middle of a world economic crisis.

Nevertheless we need to address these problems. Nowadays, due to constant change of business conditions, flexibility and adaptability are considered significant competitive advantages for an organization. To achieve this in Business and Management problems, practical problems must be solved in real time is necessary (Dašić et al. 2011). For the last 40-50 years all problems originated from Business and Management processes needed experts, in order to be solved in a realistic and costeffective way. Unfortunately, practical problems can arise at any time and experts cannot always be available. However, their knowledge could be utilized at all times in certain problematic areas with the use of a well-designed expert system (ES).

Expert Systems constitute the most commonly applied branch of Artificial Intelligence (AI). An ES is in fact a computational program, which represents and analyzes an expert's knowledge in a specific area, so as to advise or solve problems in that field. It emulates human reasoning regarding a problem by performing a complex process for decision making in a problem domain. Expert Systems, since their development have been providing us with effective solutions-answers in a variety of problemsquestions that are difficult to handle using other traditional methodologies.

Various ES methodologies (Liao 2005) have led expert systems to overcome their limitations regarding their rule-based nature. However, there is still a long way to go. ES development continues to be a time-consuming and expensive task. Additionally, they can solve complex problems in a very narrow area and it is not always easy for experts to communicate their domain-specific knowledge. ES are often mistrusted by their users, i.e. managers, who cannot get used to the idea that a computer program is going to decide instead of them. Managers seem to be fonder of tools for decision 
facilitation rather than automatic decision making. Thus they have turned to other more sophisticated methods such as Neural Networks and FCMs.

It is a common truth that the success of business management lies in the consideration and provision of how a variety of factors interact between them. Today, the number of factors that must be taken into account for an effective business management has increased significantly, due to the highly dynamic business environment. Unfortunately, many times managers lack the ability of evaluating all the related factors, as they use to analyze and assess the impact of two to three factors simultaneously at best. It is very common for a business system to contain uncertain and fuzzy knowledge, due to the fact that most knowledge is expressed in terms of cause and effect. In addition, every business practitioner, i.e. expert, tends to have its individual point of view about effective business management. Fuzzy Cognitive Maps (FCMs) have come to fill these gaps, as they are best suited for problems where experts have different opinions about a "correct" answer and they have the ability to model uncertain and fuzzy knowledge.

FCMs have comprised a tool used for decision facilitation in diverse scientific areas, such as medicine (Hatwagner 2015) and political science (Tsadiras 2003). The purpose of this study is to review recent applications of Fuzzy Cognitive Maps in the domain of B\&M systems. By doing that, it can be shown how FCMs can make life for managers a lot easier and it can be derived that FCMs can constitute a useful tool for decision support in business management, too.

This paper has been organized in the following way. Section 2 gives a brief overview of Fuzzy Cognitive Maps, while Section 3some limitations of FCMs. Section 4 presents recent applications of FCMs to various areas of business and management. In Section 5 the survey of FCMs been used in $\mathrm{B} \& \mathrm{M}$ is provided on a table and a short discussion on the survey results is given. Finally, in Section 6 , conclusions and future research topics are outlined.

\section{A Brief Overview of Fuzzy Cognitive Maps}

Fuzzy Cognitive Maps (FCMs) is a modeling technique, arising from the combination of Fuzzy Logic and Neural Networks. Compared to conventional expert systems, FCMs have considerable advantages; they are dynamic feedback systems (Taber 1991) and they can represent structured knowledge very easily, providing the higher level of abstraction needed in many cases (Lee \& Ahn 2009). FCMs constitute a useful tool, with which we take advantage and quantify the accumulated knowledge obtained through years of observing the operation and behavior of complex systems (Papageorgiou et al. 2003). Thus we can claim that Fuzzy Cognitive Maps are fuzzy structures that strongly resemble neural networks, and they have powerful and far-reaching consequences as a mathematical tool for modeling dynamical complex systems.

The term of "fuzzy cognitive map" was first used by Kosko (Kosko 1986) to illustrate a graphically signed directed graph with feedback, consisting of nodes and weighed arcs. The FCM's nodes represent the concepts used for describing system behavior. These nodes are interconnected by signed and weighted arcs, standing for the existing causal relationships between the concepts. In other words, the arcs describe the variation on the value of one concept when the value of an interconnected concept is being altered.

When concept $C_{j}$ influences concept $C_{i}$, there is a $w_{j i}$ arc which can take any value between -1 and 1 , quantifying this way the correlation between the two concepts. $\mathrm{w}_{\mathrm{ji}}$ can be:

Positive $\left(\mathrm{w}_{\mathrm{ji}}>0\right)$ when there is a positive causality between $\mathrm{C}_{\mathrm{j}}$ and $\mathrm{C}_{\mathrm{i}}$, i.e. an increase/decrease in the value of $\mathrm{C}_{\mathrm{j}}$ brings an increase/decrease in the value of $\mathrm{C}_{\mathrm{i}}$ respectively.

Negative $\left(\mathrm{w}_{\mathrm{ji}}<0\right)$ when the causality is negative and increase/decrease of the value of $\mathrm{C}_{\mathrm{j}}$ causes a decrease/increase of the value of $\mathrm{C}_{\mathrm{i}}$.

Zero $\left(\mathrm{w}_{\mathrm{ji}}=0\right)$ when there is no influence of concept $\mathrm{C}_{\mathrm{j}}$ to concept $\mathrm{C}_{\mathrm{i}}$.

The bigger the absolute value of $\mathrm{w}_{\mathrm{ji}}$ it is, the stronger the influence of $\mathrm{C}_{\mathrm{j}}$ to $\mathrm{C}_{\mathrm{i}}$ will be, in a direct (positive causality) or an inverse way (negative causality).

In a conventional FCM, the value of each concept is computed, taking into account the influence of other concepts to the specific concept (Groumpos 2010), by applying the following mathematical procedure: 


$$
A_{i_{(k+1)}}=f\left(k_{2} \cdot A_{i_{(k)}}+k_{1} \cdot \sum_{\substack{j \neq i \\ j=1}}^{N} A_{j_{(k)}} \cdot w_{j i}\right) .
$$

In (1), $\mathrm{A}_{\mathrm{i}}{ }^{(\mathrm{k}+1)}$ is the value of concept $\mathrm{C}_{\mathrm{i}}$ at time $\mathrm{k}+1, \mathrm{~A}_{\mathrm{j}}{ }^{(\mathrm{k})}$ is the value of concept $\mathrm{C}_{\mathrm{j}}$ at time $\mathrm{k}, \mathrm{w}_{\mathrm{ji}}$ is the weight of interconnection between concepts $\mathrm{C}_{\mathrm{j}}$ and $\mathrm{C}_{\mathrm{i}}$ and $\mathrm{f}$ is the sigmoid threshold function.

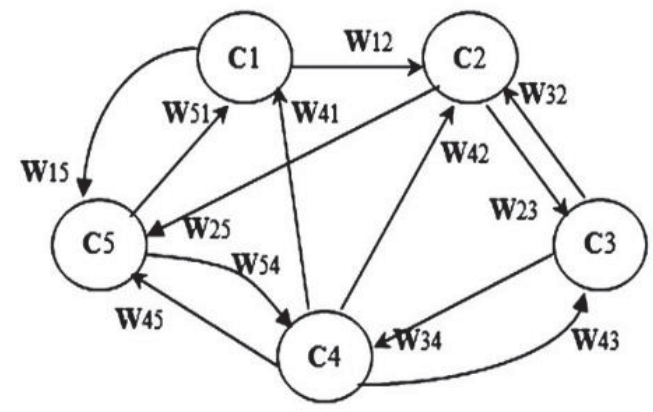

Fig. 1. A Simple Fuzzy Cognitive Map

A more detail mathematical presentation of FCMs is provided on Glykas (2010) and Groumpos (2010)

\section{Some Limitations of FCM}

In reviewing the literature, for the last 30 years it has been realized that FCMs, have strong and weak points. They are flexible, adaptable and they can model very well semi-structured or unstructured knowledge. Nevertheless, they contribute to the problem solving process only by evaluating the alternatives of a scenario, thus, not absolving the manager from making the actual decision. The preceding features suggest that FCMs cannot be utilized in all kinds of problems. They are preferred in unstructured cases, where they can provide managers with very good results without the ethical implication of human replacement. Another short come of FCMs is that present models and algorithms cannot guarantee convergence to a steady value. In addition without learning algorithms all different initial conditions give the same final value of the FCM if and when it converges. Another limitation is the way that experts are utilized in formulating the FCM model and how different expert's knowledge is taking into consideration. For B\&M processes needed reliable and real data are not easily available.

Thus although FCM provide a powerful tool for both traditional experts and non-traditional experts to model complex systems, evaluate structural differences between the knowledge held by groups and individuals, and functionally determine the dynamic outcome of this understanding, there are still issues regarding the interpretation of FCMs as artefacts of individual knowledge and group beliefs.

In this paper, a theoretical background in order to inform the collection and make interpretation of FCM as repre- sentations of shared knowledge when individual FCMs are aggregated together, compared across individuals within the context of group interaction, or created collectively by individuals within a group context and especially in B\&M.

\section{Applıcatıons of FCMs in Business and Managment}

Considering the abovementioned favorable features of the FCMs, and the overall increase of FCMrelated studies (Glykas 2010, Groumpos 2010) there has been also an increasing amount of literature on business and systems management in the last 30 years. In this work, an attempt is made to carefully review FCM research studies related to business and management and illustrate some interesting applications of them. 
Several studies have succeeded in measuring and assessing business performance using FCM. As early as 1989 and then 1992 Zhang et all. used FCM on decision analysis for business processes. Also in 1997 D. Kardaras, and G. Mentzas used FCM to analyze Business Performance Assessmen. In another work, Glykas (2013) FCMs were implemented in strategy maps, eliminating their drawbacks and providing them with competitive advantages in terms of flexibility and simulated scenarios. Results of case studies showed that the developed system could emulate effectively experts' predictions. Chytas et al. (2011) managed to develop a new proactive balanced scorecard methodology with the aid of FCMs, which were used for quantifying the imprecise causal interrelationships of key performance indicators, so as to adjust performance goals. FCMs are used as a performance modeling tool for the implementation of business performance re-engineering methodology, in order to simulate the operational efficiency of complex, imprecise functional relationship and quantify the impact of BPR activities to the business model (Xirogiannis \& Glykas 2004).

FCMs have found a great applicability in the planning process, too. Lee et al. (2013) employed FCMs to industrial marketing planning. By integrating agent and FCM technology, they managed to overcome the conventional FCMs' limitations in marketing planning. Hence, experts' opinions from different functional departments were integrated and complex, ambiguous causalities among the related variables were quantified, allowing this way a systematic what-if analysis to be carried out, in order to compare various scenarios. Comparison and evaluation of different scenarios is done in another work too (Lopez \& Salmeron 2014), in which FCMs are applied to enterprise resource planning, modeling maintenance risks. With the help of FCMs, ERP practitioners highlight the most important factors and are able to handle the maintenance risks more effectively. Kardaras and Karakostas (1999) used FCMs as a supplement to the strategic planning of information systems. This way, it could be much easier for planners to label specific IT projects and evaluate their impact on an organization. Regarding business informatics, an interesting work was that, which proposed augmented FCMs for modeling LMS critical success factors, in order to discern the necessary activities for success (Salmeron 2009)

FCMs have also addressed the growing need to assess investment decision-making processes. Irani et al. (2014) managed to shed light upon the often cloudy evaluation of IS investments by identifying, classifying and correlating the factors that affected more the IS investment evaluation with the related knowledge components. As a result, an analysis of knowledge-based decisions in the IS evaluation investment area took place. In 2004, Koulouriotis assigned FCMs to emulate investors' reasoning process, as a means for stock prediction.

Human Resources Management has also been implemented with the fuzzy cognitive mapping technique. Xirogiannis et al. (2008) attempted to model the operational efficiency of HRM activities and their impact to shareholder satisfaction. Thus, the effects of HR practices to the overall shareholder value were clearly illustrated. In another work, Oleyaei-Motlagh and Bonyadi-Naeini (2014) investigated HRM influence to Six Sigma projects implementation. The critical factors were identified, so managers knew where should focus, in order to achieve better organizational performance as far as HRM is concerned. Last but not least, FCM applications, such as modeling core value systems (Macedo \& Camarinha-Matos 2013) and relationship management (Kang et al. 2004) enable possible detection of conflicts among colleagues, doing in this manner, the work of HRM much easier. As far as e-business is concerned, Miao et al. (2007) integrated Intelligent Agents into Fuzzy Cognitive Mapping, creating the tool of Fuzzy Cognitive Agents, in order to support e-commerce applications. That new approach enabled personalized recommendations based on the online user's preferences, common preferences of other users in general and expert's knowledge. Hence, they addressed the difficulty of many users, who cannot determine what they really want, when visiting electronic commerce web-sites. Also, Lee and Ahn (2009) combined FCMs and structural equation modeling for control design support of an e-commerce web based system (ECWS), in order to achieve high ECWS performance. The FCM's fuzzy edges facilitated the representation of environmental factors, controls, implementation, and performance in ECWS, while the structural equation modeling defined the complex causal relationships among factors. In another publication, Xirogiannis and Glykas (2007) used FCMs as a means for a causal representation of dynamic e-business maturity indicators. They showed how FCMs can work as a supplement to strategic change projects, by modeling complex strategic models and quantifying the impact of strategic changes to the overall ebusiness efficiency. 
Other worth to be mentioned applications follow. Nasserzadeh et al. (2008) used FCM modeling, in order to assess customer satisfaction, a competitive advantage in today's societies, in the sector of banking industry. The Delphi methodology, which included feedback reports for everyone, was exploited for easier consensus among the experts. The resulting FCM was capable of evaluating a bank's capacities for attracting new customers and increase customer satisfaction rate. Irani et al. (2009) used fuzzy cognitive mapping to investigate the relationship between knowledge management and organizational learning. They showed that a relationship between them does exist and the constructed FCM helps them to identify factors, with which a company could evolve to a learning organization. Wang et al. (2011) used structural equation model as a supplement to FCM, in order to define the complex causal relationships among factors in a hotel environment. The constructed FCM enlightened the often cloudy context of building competitive advantages in the hotel industry and it enabled a systematic what-if analysis to be carried out, in order to compare various possible scenarios in reality. FCMs were also applied with success in the complex sector of retail industry. They led to a better implementation of collaborative planning, forecasting and replenishment (CPFR) approach, as they highlighted the related factors for CPFR success (Büyüközkan \& Vardaloğlu 2012).

\section{Discussion on Survey Results}

In section 4 a small and limited number of FCMs applications to B\&M were presented. Indeed it was difficult to find related studies prior to 1990 s and even prior to 2000s where FCMs were used in B\&M processes. This is reasonable and understandable since the notion of FCMs was introduced by Kosko in 1986. Extensive studies of FCMs took place late in the 1990s and early in 2000s. However surprisingly FCMs were used extensively in B\&M studies from the early 2000s as will be shown next.

Through a partial but not as exhaustive as needed extensive survey and classification of FCM published studies across the internet, last 15 years FCM applications in B\&M are provided in Table 1. As been expected the survey could not and did not covered all possible application of FCMs in the broad scientific area of B\&M. An effort was made to carefully review the first 6-monts of 2015, a task not so easy given that many studies, conferences and book chapters have not yet been recorded in any data base system. This should be a future research study. However Table 1 gives us some interesting statistical results. There has been a steady increase in the number of FCM-related studies in this field, especially the last 5-6 years. In particular, FCM studies regarding Business \& Management in 2014 have been increased by almost a magnitude of ten (10) compared with those fifteen (15) years ago. Similarly for the papers and/or book chapters Table 1 shows a considerable increase in numbers in the last 5 years compared to the period of 2000-2010. Considering the above mentioned facts, it is clear that FCM application in business and management has gained a considerable interest over the last five years.

It is of interest to point out that during the first 7 months of 2015 there many studies and papers that have been in the literature in which FCMs are used extensively in studies on B\&M systems. For example in Uden et al. (2015) contains the refereed proceedings of the 10th International Conference on Knowledge Management in Organizations, KMO 2015, held in Maribor, Slovenia, in August 2015. The theme of the conference was "Knowledge Management and Internet of Things" in which more than 200 papers were presented and in most of them the central point was KM in organizations and the problems were treated using extensively Fuzzy Logic, Intelligent Systems and FCMs. The interested researcher should search through the "FCM in B\&M" and would be surprised with the results. FCMs have been extensively in B\&M studies the last 2-3 years. 
Table 1. Recent FCM Studies in Business \&Management

\begin{tabular}{|c|c|c|c|}
\hline \multirow[b]{2}{*}{ Year } & \multicolumn{3}{|c|}{$\begin{array}{c}\text { Number of FCM-related studies and papers in } \\
\text { Business \& Management }\end{array}$} \\
\hline & Studies & $\begin{array}{c}\text { Journals \& } \\
\text { Book } \\
\text { Chapters }\end{array}$ & Conferences \\
\hline 2000 & 2 & 0 & 2 \\
\hline 2001 & 0 & 2 & 3 \\
\hline 2002 & 3 & 6 & 2 \\
\hline 2003 & 5 & 5 & 4 \\
\hline 2004 & 12 & 2 & 8 \\
\hline 2005 & 3 & 0 & 6 \\
\hline 2006 & 9 & 5 & 4 \\
\hline 2007 & 9 & 3 & 6 \\
\hline 2008 & 12 & 5 & 10 \\
\hline 2009 & 20 & 16 & 7 \\
\hline 2010 & 20 & 13 & 10 \\
\hline 2011 & 15 & 12 & 8 \\
\hline 2012 & 17 & 15 & 14 \\
\hline 2013 & 22 & 18 & 12 \\
\hline 2014 & 28 & 22 & 15 \\
\hline $\begin{array}{c}2015 \\
(7 \text { months })\end{array}$ & 5 & 7 & 9 \\
\hline
\end{tabular}

An earlier paper by Darlas and Groumpos (2014) covered only the survey aspects of using FCMs in B\&M systems and for a smaller period of time, the10 years 2003-2013. This study covers more than 15 years; it is a little more extensive thus the provided table of Darlas and Groumpos (2014); here also differs on the reported results even for the period 2003-2013. As a matter of fact this study has covered the whole period since 1985 almost 30 years. Indeed the earliest study that was found in which FCMs were used on B\&M studies is that Zhang et all. (1989). The important finding here is that just 3 years after Kosko (1986) has introduced for first time the concept of Fuzzy Cognitive Maps (FCMs), this new method has been used on Business studies. Thirty years later in 2010, more than 40 related "studies" (studies, papers, and book chapters) have been identified on this limited study to relate FCMs and B\&M studies. In the first seven (7) months of 2015 on the limited sources that have been searched more than 20 studies are covering this broad aspect of applying FCMs in Business and Management studies. This trend will continue with a steady increase in using FCMs in B\&M processes.

\section{Conclusions and Future Research}

Business and Management problems are characterized by controversial theories and mathematical solutions, with complex equations and formulas. These difficulties have led to an extensive use, for the period up to 2000, of Expert Systems (ES) and Intelligent Systems (IS) to address problems of this domain, thanks to their capability of taking advantage of experts' domain-specific knowledge and emulate their inference in a very narrow area. However they were not able to provide satisfactory solutions especially after 2000 when the international B\&M systems became so complicated due to their globalization. This study was set out to demonstrate the various applications of FCMs to B\&M. FCMs have been proven through the limited literature, as a very useful method and tool to identify 
and assess the key-factors of a variety of B\&M issues. A table shown the use of FCMs in B\&M systems has been presented. The results of this review, does not show the whole magnitude of the use of FCMs in B\&M systems. However it demonstrates a positive trend in using FCMs in B\&M for the last 10 years.

However, FCM technique cannot act as a panacea for solving B\&M problems as it depends upon several assumptions, such as the existence of only symmetric or monotonic causal relationships. In addition the globalized economy presents totally new, challenging and controversial problems especially when there are many and different economic conflict of interest. A lot of effort has been made for conventional FCMs to overcome their drawbacks either by using various supplements or by advancing FCM theory and learning. Future research directions could include: develop new B\&M systems for special purposes using FCMs use real data to validate the new models. Study the behavior of B\&M systems using Existing FCM methods and tools. We need to research more, how studying the historical knowledge of B\&M processes leads us to wise decisions in the future. See plenary paper (Groumpos 2015) of this conference. Despite their drawbacks though, the increasing number of FCMs' applications not only in various aspects of business, but also in diverse scientific fields, seems quite promising.

\section{References}

1 Büyüközkan, G. and Vardaloğlu, Z. (2012). Analyzing of CPFR success factors using fuzzy cognitive maps in retail industry. Expert Systems with Applications, 39(12), pp.10438-10455.

2 Chytas, P., Glykas, M. and Valiris, G. (2011). A proactive balanced scorecard. International Journal of Information Management, 31(5), pp.460-468.

3 Darlas, O.D and Groumpos, P. P. (2014)A Survey on Applications of Fuzzy Cognitive Maps in Business and Management. In Proc. of the International Conference

4 "Information Technologies for Intelligent Decision Making Support" May 2014. Ufa, Russia

5 Dašić, M., Trajković, S. and Tešanović, B. (2011). The necessity of using expert systems in strategic decision making. International Journal of Economics \& Law, 1(1), pp.27-35.

6 Glykas, M. (2010). Fuzzy cognitive maps. Berlin: Basic Theories and their Application to Complex Systems. In: M. Glykas, ed., Fuzzy Cognitive Maps: Advances in Theory, Methodologies, Tools and Applications, Springer-Verlag Berlin Heidelberg.

7 Glykas, M. (2013). Fuzzy cognitive strategic maps in business process performance measurement. Expert Systems with Applications, 40(1), pp.1-14.

8 Groumpos, P.P. (2010). Fuzzy Cognitive Maps: Basic Theories and their Application to Complex Systems. In: M. Glykas, ed., Fuzzy Cognitive Maps: Advances in Theory, Methodologies, Tools and Applications, Springer-Verlag Berlin Heidelberg, pp.1-22.

9 Groumpos, P. P. (2015), The Need for Wise Decision Making Support Systems (WDMSS) In Developing Future Intelligent Systems. (this conference, TECIS 2015)

10 Hatwagner, M. (2015). Introduction of Modeling Complex Management Systems using Fuzzy Cognitive Map. In: 7th International Conference on Information Technology ICIT. pp.508-514.

11 Irani, Z., Sharif, A., Kamal, M. and Love, P. (2014). Visualising a knowledge mapping of information systems investment evaluation. Expert Systems with Applications, 41(1), pp.105125.

12 Irani, Z., Sharif, A. and Love, P. (2009). Mapping knowledge management and organizational learning in support of organizational memory. International Journal of Production Economics, 122(1), pp.200-215.

13 Kang, I., Lee, S. and Choi, J. (2004). Using fuzzy cognitive map for the relationship management in airline service. Expert Systems with Applications, 26(4), pp.545-555.

14 Kardaras, D. and Karakostas, B. (1999). The use of fuzzy cognitive maps to simulate the information systems strategic planning process. Information and Software Technology, 41(4), pp.197-210.

15 Kardaras, D., and Mentzas, G. (1997). Using fuzzy cognitive maps to model and analyze business performance assessment. In Prof. of Int. Conf. on Advances in Industrial Engineering-Applications and Practice II , pp. 63-68.

16 Kosko, B. (1986). Fuzzy cognitive maps. International Journal of Man-Machine Studies, 24(1), pp.65-75. 
17 Koulouriotis, D. (2004). Investment analysis \& decision making in markets using adaptive fuzzy causal relationships. Operational Research, 4(2), pp.213-233.

18 Lee, S. and Ahn, H. (2009). Fuzzy cognitive map based on structural equation modeling for the design of controls in business-to-consumer e-commerce web-based systems. Expert Systems with Applications, 36(7), pp.10447-10460.

19 Lee, K., Lee, H., Lee, N. and Lim, J. (2013). An agent-based fuzzy cognitive map approach to the strategic marketing planning for industrial firms. Industrial Marketing Management, 42(4), pp.552-563.

20 Liao, S. H. (2005). Expert system methodologies and applications - a decade review from 1995 to 2004. Expert Systems with Applications, 28(1), pp.93-103.

21 Lopez, C. and Salmeron, J. (2014). Dynamic risks modelling in ERP maintenance projects with FCM. Information Sciences, 256, pp.25-45.

22 Miao, C., Yang, Q., Fang, H. and Goh, A. (2007). A cognitive approach for agent-based personalized recommendation. Knowledge-Based Systems, 20(4), pp.397-405.

23 Oleyaei-Motlagh, S. and Bonyadi-Naeini, A. (2014). Identifying the role of human resource management in increasing performance and implementation of six sigma projects using fuzzy cognitive maps. 10.5267/j.uscm, 2(3), pp.179-190.

24 Papageorgiou, E. (2011). Review study on fuzzy cognitive maps and their applications during the last decade. In: 2011 IEEE International Conference on Fuzzy Systems. IEEE Computer Society, pp.828-835.

25 Papageorgiou, E., Stylios, C. and Groumpos, P. (2003). Fuzzy Cognitive Map Learning Based on Nonlinear Hebbian Rule. In: AI 2003: Advances in Artificial Intelligence Lecture Notes in Computer Science, Springer Berlin Heidelberg, pp.256-268.

26 Reza Nasserzadeh, S., Hamed Jafarzadeh, M., Mansouri, T. and Sohrabi, B. (2008). Customer Satisfaction Fuzzy Cognitive Map in Banking Industry. In: Communications of the IBIMA, 2 (21). pp.151-162.

27 Salmeron, J. (2009). Augmented fuzzy cognitive maps for modelling LMS critical success factors.Knowledge-Based Systems, 22(4), pp.275-278.

28 Taber, R. (1991). Knowledge processing with Fuzzy Cognitive Maps. Expert Systems with Applications, 2(1), pp.83-87.

29 Tsadiras, A., Kouskouvelis, I. and Margaritis, K. (2003). Using Fuzzy Cognitive Maps as a Decision Support System for Political Decisions. In: Advances in Informatics, Springer Berlin Heidelberg, pp.172-182.

30 Uden, L., Heričko, M. and Ting, I. ed., (2015). Knowledge Management in Organizations: 10th International Conference, KMO 2015. Maribor, Slovenia, Proceedings (Vol. 224). Springer.

31 Wang, C., Chen, S. and Chen, K. (2011). Using fuzzy cognitive map and structural equation model for market-oriented hotel and performance. African Journal of Business Management, 5(28), pp.11358-11374.

32 Xirogiannis, G., Chytas, P., Glykas, M. and Valiris, G. (2008). Intelligent impact assessment of HRM to the shareholder value. Expert Systems with Applications, 35(4), pp.2017-2031.

33 Xirogiannis, G. and Glykas, M. (2007). Intelligent modeling of e-business maturity. Expert Systems with Applications, 32(2), pp.687-702.

34 Xirogiannis, G. and Glykas, M. (2004). Fuzzy Causal Maps in Business Modeling and Performance-Driven Process Re-engineering. Methods and Applications of Artificial Intelligence Lecture Notes in Computer Science, pp.334-351.

35 Zhang W.R, Chen S.S, Bezdek J.C,(1989) Pool2: A generic

36 system for cognitive map development and decision

37 analysis, IEEE Transactions on Systems, Man, and

38 Cybernetics 19 (1)

39 Zhang, W., Chen, S., Wang, W. and King, R. (1992). A cognitive-map-based approach to the coordination of distributed cooperative agents. IEEE Transactions on Systems, Man, and Cybernetics, 22(1), pp.103-114. 